\title{
Granulomatous vaginal ulceration due to metastatic cutaneous Crohn's disease
}

\author{
Hugh J FreEMAN MD, RAYMOND KWONG MD, STEPHEN L SACKS MD
}

\begin{abstract}
HJ FREEMAN, R KWONG, SL SACKS. Granulomatous vaginal ulceration due to metastatic cutaneous Crohn's disease. Can J Gastroenterol 1995;9(4):183186. A 28-year-old woman with a prior history of Crohn's disease was evaluated for painful vaginal ulceration in 1984. Subsequent studies revealed isolated involvement of the vagina with a granulomatous inflammatory process characteristic of metastatic cutaneous Crohn's disease. Conservative symptomatic treatment was associated with resolution and no subsequent recurrence of genital tract disease.
\end{abstract}

Key Words: Granulomatous vaginitis, Herpes simplex vaginitis, Metastatic cutaneous Crohn's disease, Sexually transmitted diseases, Vaginal ulcers

\section{Ulcération vaginale granulomateuse attribuable à une maladie de Crohn cutanée métastatique}

RÉSUMÉ : Une femme de 28 ans présentant des antécédents de maladie de Crohn a été examinée pour ulcération vaginale douloureuse en 1984. Les examens subséquents ont révélé une atteinte isolée du vagin due à un processus inflammatoire granulomateux caractéristique d'une maladie de Crohn cutanée métastatique. Un traitement conservateur des symptômes s'est révélé efficace et aucune récurrence subséquente de la maladie des voies génitales ne s'est manifestée.

$\mathrm{C}$ ROHN'S DISEASE MAY INVOLVE the vulva due to continuous extension of the anal, rectal and/or colonic inflammatory process with indolent, undermined perineal ulceration showing granulomatous inflammation (1-3). In addition, direct enteric fistulous communication with the genitourinary tract may occur. Fi-

nally, vaginal or other cutaneous lesions (ie, erosions, ulcers) separated from the gastrointestinal tract by normal skin (ie, 'skip lesions') have very rarely been reported in Crohn's disease; in the case of genital disease, these are generally characterized by the absence of perineal and/or perianal disease and histologically by the presence of giant

Department of Medicine (Gastroenterology and Infectious Diseases), University of British Columbia, Vancouver, British Columbia

Correspondence and reprints: Dr Hugh Freeman, ACU F-137, Gastroenterology,

Vancouver Hospital (UBC Site), 2211 Wesbrook Mall, Vancouver, British Columbia

V6T 1W5. Telephone 604-822-7216

Received for publication October 20, 1994. Accepted October 21, 1994

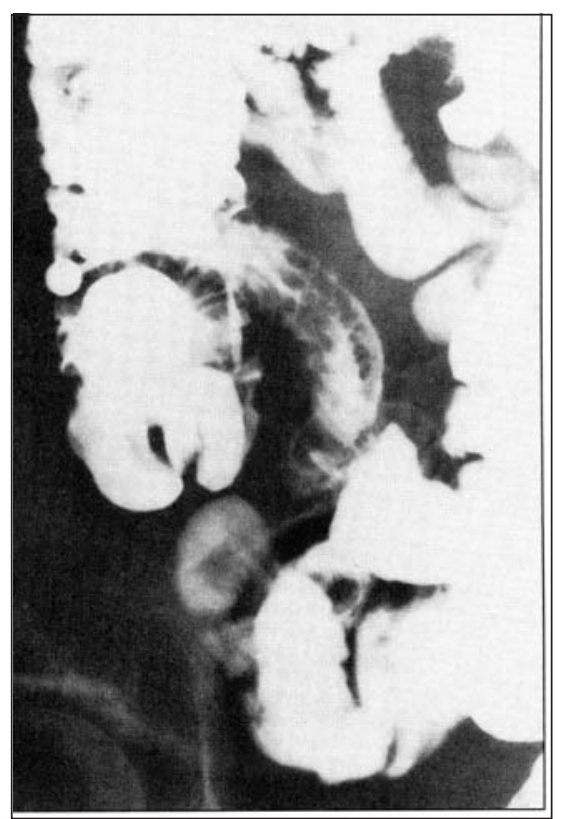

Figure 1) Barium radiograph showing ileal mucosal ulceration and narrowing with Crohn's disease

cells, noncaseating granulomas or both (4-8). This phenomenon, called 'metastatic' cutaneous Crohn's disease (MCCD) (9-13), appears to have a variable clinical course, but requires careful differentiation from other, especially infectious, causes.

The present patient was initially referred to a sexually transmitted diseases clinic for evaluation of painful vaginal ulcers thought to be due to herpes simplex virus. Clinical assessment of the vaginal lesions, however, suggested a different cause. Studies to exclude 


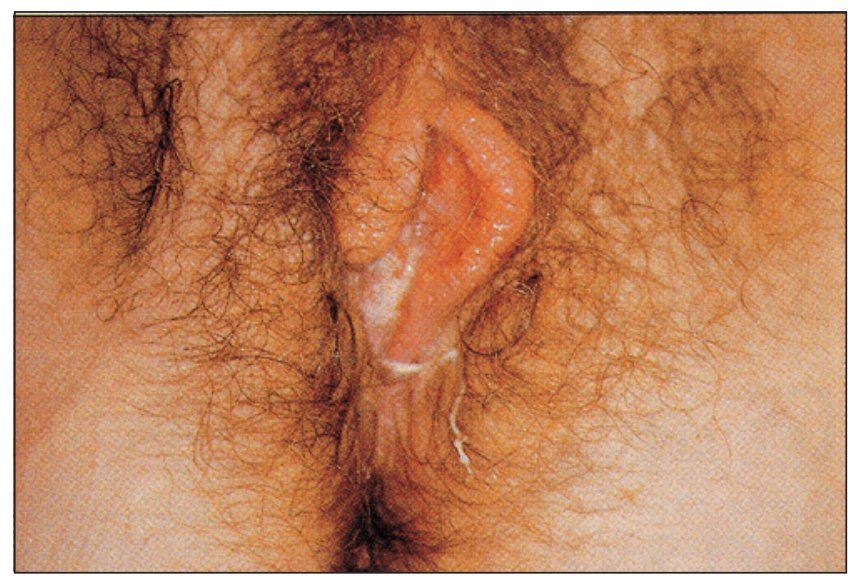

Figure 2) Vulvovaginal swelling and ulceration with exudate. Perianal area is not involved

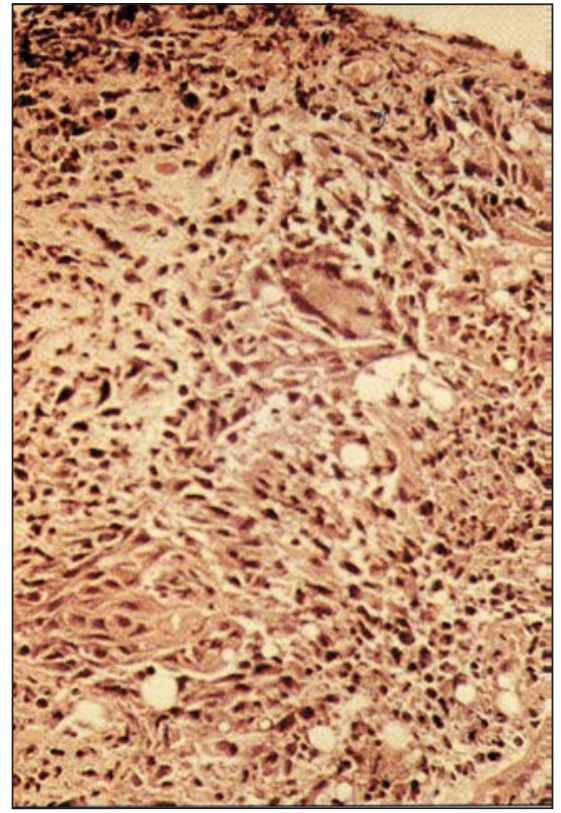

Figure 4) Vaginal mucosal biopsy showing acute and chronic granulomatous inflammatory process with multinucleated giant cell

other (especially infectious) etiologies, combined with features of previously diagnosed Crohn's disease, led to a diagnosis of MCCD of the vagina.

\section{CASE PRESENTATION}

A 28-year-old Caucasian female was initially seen at a community hospital in April 1984 with intermittent fever, malaise, weight loss, abdominal pain and diarrhea for one year. Examination revealed multiple oral aphthous ulcers and right lower quadrant tenderness. Investigations showed hemoglobin $116 \mathrm{~g} / \mathrm{L}$, white blood cell count $11,500 /$ $\mathrm{mm}^{3}$ and platelet count $567,000 / \mathrm{mm}^{3}$.

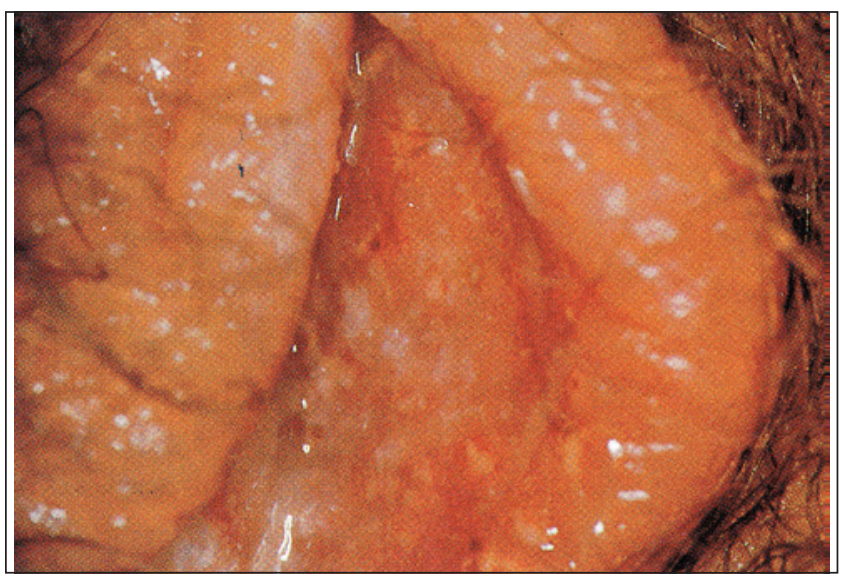

Figure 3) Vulvovaginal swelling with erosions, ulceration and exudate
Erythrocyte sedimentation rate was $40 \mathrm{~mm} / \mathrm{h}$ (normal up to 20). Urinalysis and sigmoidoscopy were normal. Barium radiographs revealed narrowing of the ileal lumen for approximately $15 \mathrm{~cm}$ with mucosal swelling and ulceration, consistent with Crohn's disease (Figure 1). An ${ }^{111}$ In autologous whole body white blood cell scan showed abnormal activity in the region of the ileum, cecum, and ascending and transverse colon consistent with Crohn's disease. Treatment included sulfasalazine and prednisone, but nausea and vomiting developed with increased abdominal pain. Because of possible drug intolerance, medications were discontinued and gastrointestinal symptoms resolved.

In August 1984, the patient developed bilateral vaginal labial pain. Oral and pharyngeal aphthous ulcers were present involving the right tonsillar pillar, floor of the mouth, tongue and hard palate. Indirect laryngoscopy was normal. There were no gastrointestinal symptoms. Rectal and pelvic examinations were normal. Over the next three weeks, however, vaginal pain persisted and progressive swelling with ulceration of the labia minora developed.

She was referred to a sexually transmitted diseases clinic at University Hospital in Vancouver, British Columbia in October 1984. There was no history of known sexually transmitted disease nor sexual activity during the previous two years. Examination showed multiple aphthous ulcers of the palate and buccal mucosa, bilateral episcleritis and swollen labia minora with multiple superficial erosions and ulcerations to, but not extending through, the introitus (Figures 2,3). The cervix was normal. There was no cervical or inguinal adenopathy. Abdominal and rectal examination, flexible sigmoidoscopy and rectal biopsy were normal.

Investigations revealed hemoglobin $123 \mathrm{~g} / \mathrm{L}$, normal red blood cell indexes, white blood cell count $7500 / \mathrm{mm}^{3}$ with a normal differential and platelet count $414,000 / \mathrm{mm}^{3}$. Venereal Disease Research Laboratory test was negative. Blood urea nitrogen, serum creatinine, calcium, glucose, folic acid, vitamin $\mathrm{B}_{12}$, iron, iron binding capacity and protein electrophoresis were normal.

Fecal studies for ova and parasites, salmonella, shigella, campylobacter, aeromonas, yersinia (14), Clostridium difficile and $\mathrm{C}$ difficile cytotoxin were negative. Vaginal and cervical cultures for viruses, including herpes simplex, chlamydia, trichomonas, candida and Haemophilus ducreyi, were negative. Vaginal labial biopsy showed focal ulceration with an acute and chronic inflammatory infiltrate, as well as granulomatous inflammation with giant cells (Figure 4). Special stains and cultures for acid-fast organisms and fungi were negative.

The patient's symptoms and vaginal lesions improved over two to three weeks; pain symptoms were initially controlled with codeine and acetaminophen along with local cleansing 
with sitz baths. By December 1984, the patient was completely asymptomatic with no persisting vaginal lesions; she has remained well since that time with no further gastrointestinal or gynecological symptoms.

\section{DISCUSSION}

Crohn's disease may involve all parts of the gastrointestinal tract as well as extraintestinal sites, including the genital tract. The term 'metastatic cutaneous Crohn's disease' has been used to describe involvement remote from the gastrointestinal tract, ie, 'skip lesions', separated from the gastrointestinal tract by normal intact skin.

In the extraintestinal tract manifestations of Crohn's disease, involvement of the skin is common; indeed, 20 to $40 \%$ of Crohn's disease patients may have dermatological features. MCCD, however, is rare, with fewer than 30 reported cases in the literature (4-13, 15-20). The lesion of MCCD may manifest as an ulcer, nodule or plaque and has been identified principally in the retroauricular region and inframammary area, as well as the face, upper and lower extremities, umbilicus, lower abdominal wall, penis and vulva. It appears that ulceration occurs primarily in sites of apposition of moist skin surfaces (3).

The clinical appearance of MCCD is relatively distinctive, and it should be possible, on clinical grounds alone, to differentiate this condition from other dermatological entities associated with Crohn's disease. For example, pyoREFERENCES

1. Parks AG, Morson BC, Pegum JS.

Crohn's disease with cutaneous involvement. Proc R Soc Med 1965;58:241-2.

2. McCallum DI, Kinmont PDC. Dermatologic manifestations of Crohn's disease. Br J Dermatol 1968;80:1-8.

3. Mountain JC. Cutaneous ulceration in Crohn's disease. Gut 1970;11:18-26.

4. Ansell ID, Hogbin B. Crohn's disease of the vulva. J Obstet Gynecol Br Commonwealth 1973;80:376-8.

5. Kao MS, Paulson JD, Askin FB. Crohn's disease of the vulva. Obstet Gynecol 1975;46:329-33.

6. Levine EM, Barton JJ, Grier EA. derma gangrenosum typically begins with a crop of small, discrete pustules that ulcerate, while erythema nodosum presents as tender, erythematous nonulcerated nodules, characteristically located on the anterior tibial surfaces. Neither of these resembles the MCCD lesion. Histologically, granulomatous inflammation with giant cells and/or discrete noncaseating granuloma is present. The MCCD lesion correlates poorly with disease activity. Indeed, rare patients have been recorded with perineal involvement alone and no gastrointestinal disease (21).

A number of specific criteria are required to diagnose MCCD: first, cutaneous lesions, typically erosions or ulcerations, must be separated from intestinal tract by normal skin, ie, 'skip lesion'; second, pathological demonstration of an inflammatory reaction characterized by giant cells and noncaseating granulomas is required; and third, other causes of granulomatous vulvovaginitis, particularly infectious, require exclusion. MCCD may also resemble other, primarily granulomatous, cutaneous conditions, ie, fungal and mycobacterial infections, sarcoidosis, necrobiotic granulomas and foreign body reactions.

MCCD is a rare cause of genital ulcers; other possibilities should be considered (22,23). Stevens-Johnson syndrome may also have other ulcers (ie, mouth, eyes), sometimes with target 'iris' lesions on the skin. In addition to genital ulcers, Reiter's syndrome includes an iritis with balanitis and arthritis, while Behçet's syndrome Metastatic Crohn's disease of the vulva. Obstet Gynecol 1982;60:395-7.

7. Devroede G, Schlaeder G, Sanchez G, Haddad H. Crohn's disease of the vulva. Am J Clin Pathol 1975;63:348-58.

8. Kremer M, Nussenson E, Steinfeld M, Zuckerman P. Crohn's disease of the vulva. Am J Gastroenterol 1984;79:376-8.

9. Sutphen JL, Cooper PH, Mackel SE, Nelson DL. Metastatic cutaneous Crohn's disease. Gastroenterology 1984;86:941-4.

10. McCallum DI, Gray WM. Metastatic Crohn's disease. Br J Dermatol 1976;95:551-4.

11. Tweedie JH, McCann BG. Metastatic includes iritis, erythema nodosum and recurrent oral ulcers. All these syndromes may be immunologically mediated. Many infectious causes often show particular features that aid in their diagnosis. Syphilitic chancre may be solitary or multiple, well demarcated and, usually, indurated with minimal or no pain. Herpes infection typically presents as an initial inflammatory stage followed by cell swelling and death with superficial clustered vesicles, ulcers or both. In the immunocompromised host, this virus can also cause deep and undermined ulcers. Chancroid, however, presents as a pustule that ulcerates with ragged edges and a red granular base. Solitary or multiple lesions may occur due to auto-inoculation. Both genital herpes and chancroid are exquisitely tender to touch or to urine contact.

MCCD is an unusual cause of genital ulceration, and a broad range of possibilities require consideration and exclusion in the patient with Crohn's disease. Treatment of MCCD, however, still needs more critical evaluation. Numerous modalities have been employed, including topical zinc and/or systemic steroids $(3,7,15,17)$, oral and intravenous antibiotics, particularly metronidazole $(7,8,15-18)$ and immunosuppressive agents, including 6mercaptopurine (8), and surgical excision $(3,16)$. Occasionally (3), symptomatic measures alone have been associated with complete healing of MCCD.

Crohn's disease of thigh and forearm. Gut 1984;25:213-4.

12. Liebermann TR, Greene JF. Transient subcutaneous granulomatosis of the upper extremities in Crohn's disease. Am J Gastroenterol 1979;72:89-90.

13. Burgdorf W, Orkin M. Granulomatous perivasculitis in Crohn's disease. Arch Dermatol 1981;117:674-5.

14. Watkins S, Quan L. Vulvovaginitis caused by Yersinia enterocolitica. Pediatr Infect Dis 1984;3:444-5.

15. Duhra P. Metastatic Crohn's disease responding to metronidazole. Br J Dermatol 1988;119:87-91.

16. Holohan M, Coughlan M, 
O'Loughlin S, Dervan P. Crohn's disease of the vulva. Br J Obstet Gynaecol 1988;95:943-5.

17. Case records of the Massachusetts General Hospital. Case 26-1989. N Engl J Med 1989;320:1741-7.

18. Werlin SL, Esterly NB, Oechler H. Crohn's disease presenting as unilateral labial hypertrophy. J Am Acad

Dermatol 1992;27:893-5.

19. Shum DT, Guenther L. Metastatic Crohn's disease: case report and a review of the literature. Arch Dermatol 1990;126:645-8.

20. Buckley C, Bayoumi A-HM, Sarkany I. Metastatic Crohn's disease Clin Exp Dermatol 1990;15:131-3.
21. Bernstein LH. Healing of perineal Crohn's disease with metronidazole. Gastroenterology 1980;79:357-65.

22. Sacks SL. Genital ulcers. Syphilis, herpes and chancroid. Medicine North Am 1983;526-32.

23. Yang TC, Sacks SL. Deciphering genital ulcers. Med North Am 1990;10:1171-7. 


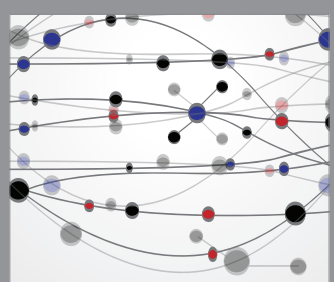

The Scientific World Journal
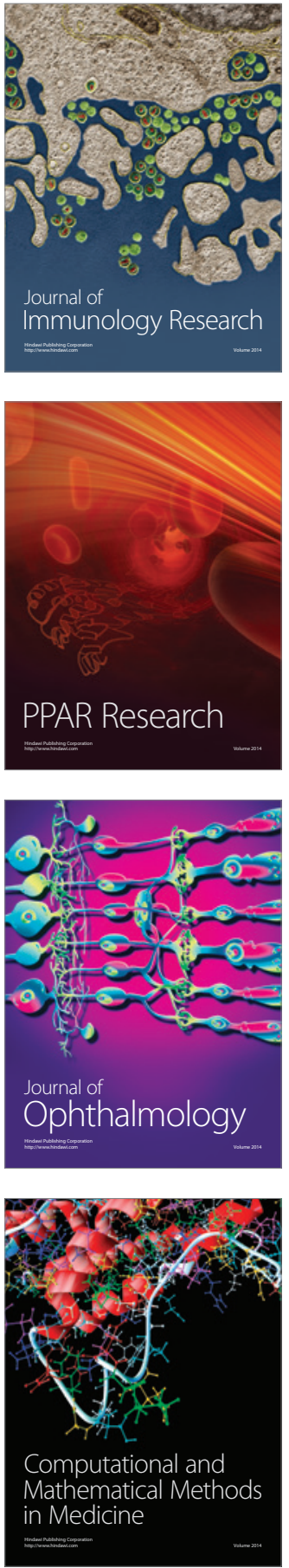

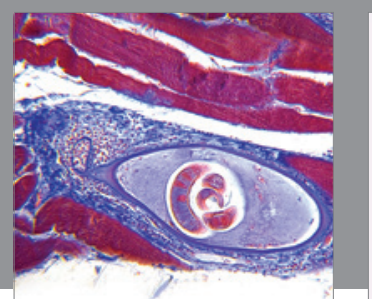

Gastroenterology Research and Practice

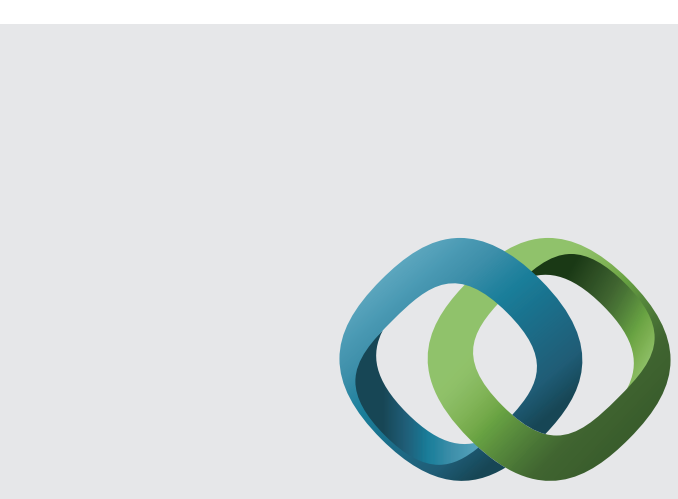

\section{Hindawi}

Submit your manuscripts at

http://www.hindawi.com
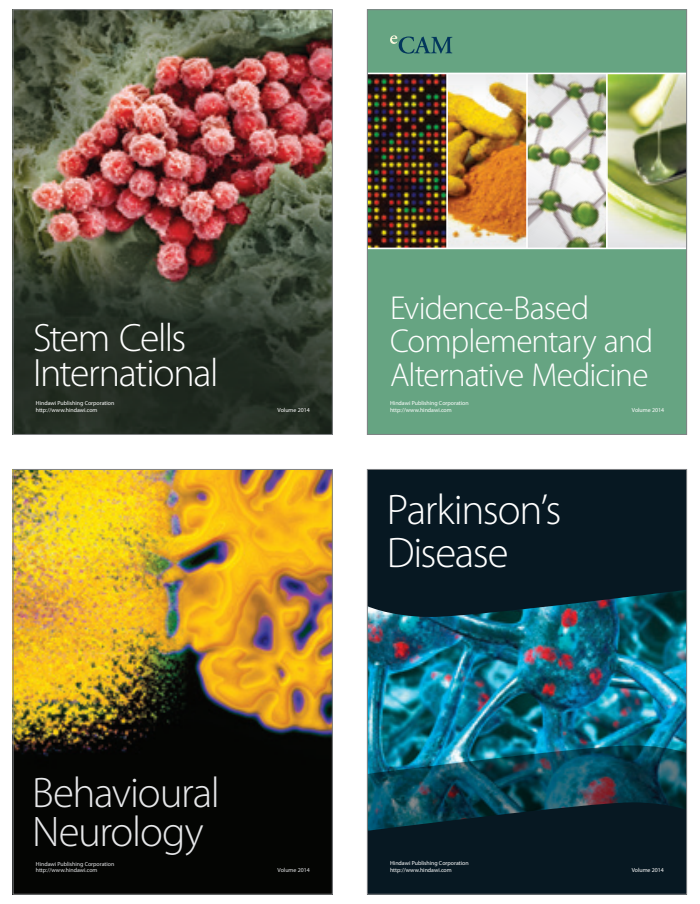
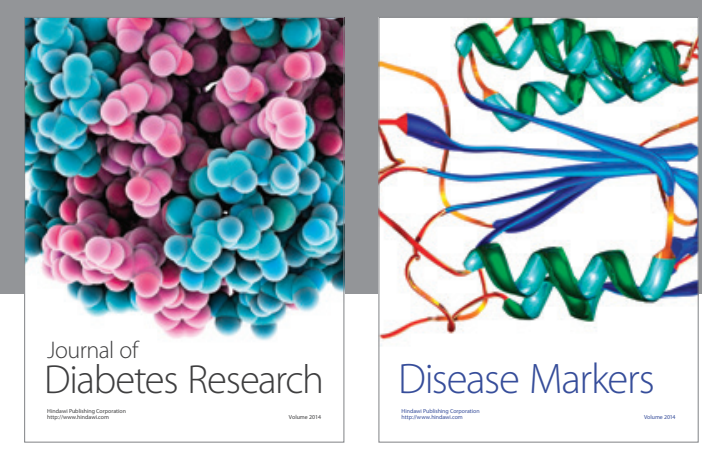

Disease Markers
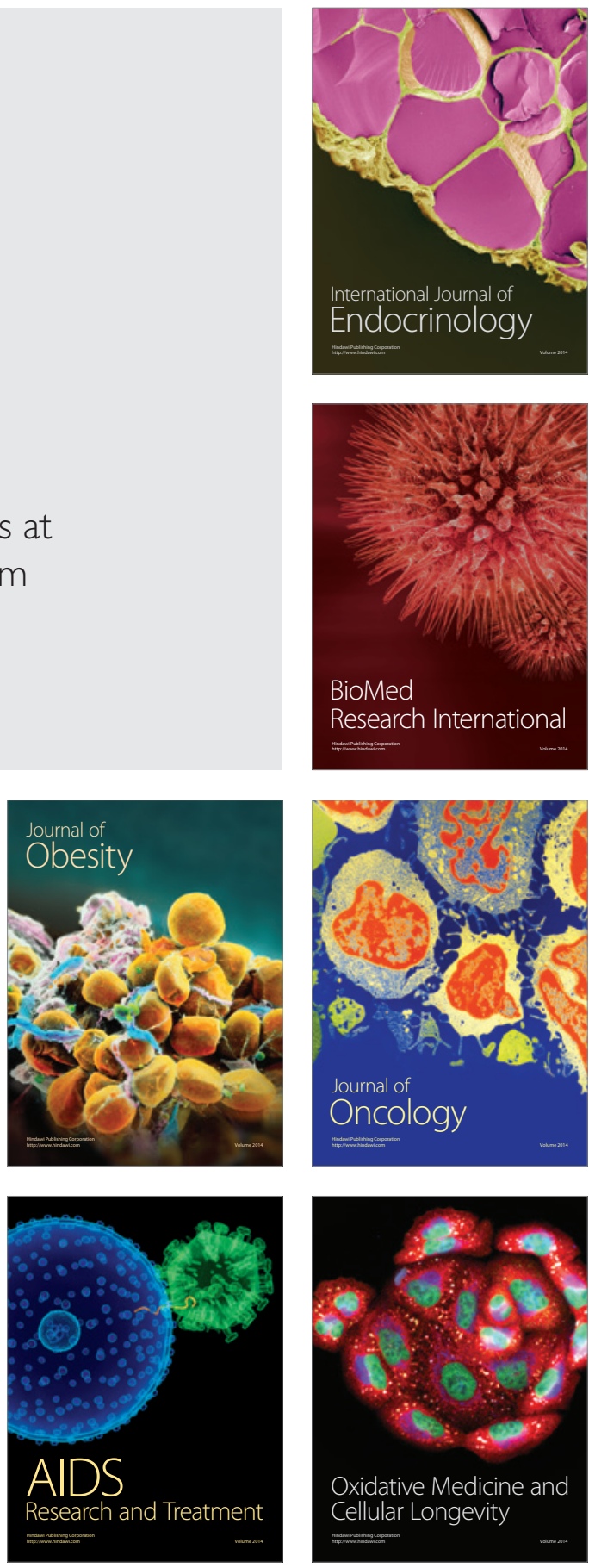